\title{
The Influence of Process Fluids on the Properties of the Surface Layer of Machined Compo- nents
}

Jan Jersák, Lucie Vrkoslavová

Department of Machining and Assembly, Faculty of Mechanical Engineering, Technical University of Liberec. E-mail: jan.jersak@tul.cz

MicroScan 600-1 is a digital Barkhausen noise analyzer. It is designed for fast nondestructive surface quality control and subsurface layers of machine parts from ferromagnetic materials and for evaluating of defects which are caused by changes of residual stresses. By the instrument based on an analysis of the Barkhausen noise is determined the value of magnetoelastic parameter. Experiments which evaluated the influence of different types of process fluids to the machining process and technological properties of the machined parts from constructional steel 16MnCr (ČSN 14 220) were carried out in the laboratory of the Department of Machining and Assembly at TU in Liberec. Turned, milled and grinded test samples by using five different types of process fluids were evaluated using the analyzer. For The comparison was machining carried out also without inlet process fluid, i.e. "dry" and with the process fluid - water. Measurements of magnetoelastic parameter were performed repeatedly and measured values were statistically processed. The paper presents the resulting values of this parameter showing the influence of process fluids on the properties of the surface layer of the machined parts.

Keywords: machining, process fluids, surface integrity, magnetoelastic parameter

\section{Acknowledgement}

This paper was implemented with financial support from the state budget through the Czech Republic-Technology Agency of the Czech Republic (project TA02021332) and it's related to the investigation on the Specific University Research Projects which are supported by the Ministry of Education (MSMT) of the Czech Republic.

\section{References}

[1] POPOV, Alexey, LICEK, Roman. The influence of process fluids from PARAMO a. s. on the surface roughness in turning. Strojírenská technologie, 2012, roč. XVI, č. 1 a 2, s. 60 - 64. ISSN 1211-4162.

[7] MALEC, Jiří. Některé př́lilš neznámé pojmy. Strojírenská technologie, 2006, roč. XI., č. 3, s. 4-5. ISSN 12114162.

[8] HOLEŠOVSKÝ, František. Stanovení zbytkových napětí v povrchu po obrábění. Strojirrenská technologie, 2006, roč. XI, č. 3, s. 29-32. ISSN 1211-4162.

[9] VRKOSLAVOVÁ, Lucie, BAKALOVÁ, Totka. Hodnocení zbytkových napětí metodou analýzy Barkhausenova šumu v porovnání s RTG difrakcí. Jemná mechanika optika, 2013, roč. 58, č. 1, s. 11-13. ISSN 0447-6441.

[10] OCHODEK, Vladislav. Využití Barkhausenova šumu ke kontrole a optimalizaci procesu broušení. Strojírenská technologie, 2006, roč. XI., č. 3, s. 17-21. ISSN 1211-4162.

[11] GUPTA, H., ZHANG, M., PARAKKA, A. P., Barkhausen effect in ground steels. Acta Materialia, 1997, roč. 45, č. 5, s. 1917-1921, ISSN 1359-6454.

[12] STEWART, D. M., STEVENS, K. J., KAISER, A. B. Magnetic Barkhausen noise analysis of stress in steel. Current Applied Physics, 2004, č. 4, s. 308-311, ISSN 1567-1739.

[13] BUMBÁLEK, Bohumil, MALEC, Jiř́. Dokončovací operace a jejich význam pro funkci součástí. Strojirenská technologie, 2006, roč. XI., č. 3, s. 25-28. ISSN 1211-4162.

[14] MÁDL, J. Vliv řezných kapalin na obráběcí proces a metodika jejich testování. In: Reotrib 2000. 1. vyd. Praha: Vysoká škola chemicko-technologická, 2000, s. 93-102, ISBN 80-7080-381-9.

[15] BUMBÁLEK, L., Zbytková napětí určovaná pomoci Barkhausenova šumu. Strojírenská technologie, 2004, roč. IX, č. 3, s. 11-15, ISSN 1211-4162.

[16] MÁDL, J., HOLEŠOVSKÝ, F., aj. Integrita obrobených povrchů z hlediska funkčních vlastností. 1. vyd. Ústí nad Labem: UJEP, FVTM, Ústí nad Labem, 2008. 230 s. ISBN 978-80-7414-095-2.

[17] ČUBAN, J., CALONIUS, O., PIETOLA, M., JERSÁK, J. Fatigue life and surface integrity measurements of S355J2 steel used in hydraulic components. Manufacturing Technology, Vol. 11, December 2011, č. -. s. 5 - 11. ISSN 1213-2489, ISBN 978-80-7414-415-8. 
[18] GANEV, N., KOLAŘÍK, K., BLÁHOVÁ O., JERSÁK, J. Characteristics of Surface Integrity and Tribological Behaviour of Hardened Steels. Materials Engineering Vol. 16 (2009), No. 3a, pp. 68 - 72, ISSN 1335-0803.

[19] JERSÁK, J., GANEV, N., KOVALČÍK, J., DVOŘÁČKOVÁ, Š., KARÁSEK, J., HOTǍ̌, A. Surface integrity of hardened bearing steel after milling. Manufacturing Technology, roč. 10, December 2010, č. -. s. 80 - 87 . ISSN 1213-2489, ISBN 978-80-7414-325-0.

[20] PALA, Z., GANEV, N., KOLAŘÍK, K., BLÁHOVÁ, O., JERSÁK, J. Surface integrity and tribological behaviour of hardened steels. Chemické listy. roč. 105, 2011, č. 17. s. 739 - 742. ISSN 0009-2770.

[21] JERSÁK, J., REJZEK, M. Účinek procesní kapaliny na proces soustružení a vybrané parametry integrity povrchu. Strojírenská technologie, roč. 16, duben 2011, č. 2. s. 17 - 23. ISSN 1211-4162. 